\title{
L-Band Relative Permittivity of Organic Soil Surface Layers-A New Dataset of Resonant Cavity Measurements and Model Evaluation
}

\author{
Simone Bircher ${ }^{1, *}$, François Demontoux ${ }^{2}$, Stephen Razafindratsima ${ }^{2}$, Elena Zakharova ${ }^{3}$, \\ Matthias Drusch ${ }^{4}$, Jean-Pierre Wigneron ${ }^{5}$ and Yann H. Kerr ${ }^{1}$ \\ 1 CESBIO, Université de Toulouse, CNES/CNRS/IRD/UPS, 31400 Toulouse, France; yann.kerr@cesbio.cnes.fr \\ 2 Laboratoire de l'Intégration du Matériau au Système, Bordeaux University, 33405 Talence, France; \\ francois.demontoux@u-bordeaux.fr (F.D.); stephenholi@yahoo.fr (S.R.) \\ 3 Laboratoire d'Etudes en Géophysique et Océanographie Spatiales, 31400 Toulouse, France; \\ elena.zakharova@legos.obs-mip.fr \\ 4 European Space Agency, ESTEC, 2200 AG Noordwijk, The Netherlands; Matthias.Drusch@esa.int \\ 5 ISPA, INRA Institut National de la Recherche Agronomique, 33883 Villenave d'Ornon, France; \\ jean-pierre.wigneron@inra.fr \\ * Correspondence: simone.bircher@cesbio.cnes.fr; Tel.: +33-561-558-544
}

Academic Editors: Nicolas Baghdadi and Prasad S. Thenkabail

Received: 26 October 2016; Accepted: 8 December 2016; Published: 16 December 2016

\begin{abstract}
Global surface soil moisture products are derived from passive L-band microwave satellite observations. The applied retrieval algorithms include dielectric models (relating soil water content to relative permittivity) developed for mineral soils. First efforts to generate equivalent models for areas where organic surface layers are present such as in the high-latitude regions have recently been undertaken. The objective of this study was to improve our still insufficient understanding of L-band emission of organic substrates in prospect of enhancing soil moisture estimations in the high latitudes undergoing most rapid climatic changes. To this end, L-band relative permittivity measurements using a resonant cavity were carried out on a wide range of organic surface layer types collected at different sites. This dataset was used to evaluate two already existing models for organic substrates. Some samples from underlying mineral layers were considered for comparison. In agreement with theory the bulk relative permittivity measured in organic substrate was decreased due to an increased bound water fraction (where water molecules are rotationally hindered) compared to the measured mineral material and corresponding output of the dielectric model for mineral soils used in satellite algorithms. No distinct differences in dielectric response were detected in the measurements from various organic layer types, suggesting a generally uniform L-band emission behavior. This made it possible to fit a simple empirical model to the data obtained from all collected organic samples. Outputs of the two existing models both based on only one organic surface layer type were found to lie within the spread of our measured data, and in close proximity to the derived simple model. This general consensus strengthened confidence in the validity of all these models. The simple model should be suitable for satellite soil moisture retrieval applications as it is calibrated on a wide range of organic substrate types and the entire wetness range, and does not require any auxiliary input that may be difficult to obtain globally. This renders it generically applicable wherever organic surface layers are present.
\end{abstract}

Keywords: SMOS; passive microwave remote sensing; L-band; soil moisture; organic soil; relative permittivity 


\section{Introduction}

Due to significantly reduced microbial activity pronounced soil carbon reservoirs have been accumulating in the circumpolar northern cold climate zone (boreal forest/tundra), outweighing the vegetation and atmospheric carbon pools together [1,2]. At the same time, the higher Northern latitudes are especially sensitive to climate change due to above-average rising temperatures (e.g., [3,4]). At present still mostly locked in permafrost, there is a high potential that on thawing, this storage is subject to release to the atmosphere in form of greenhouse gases or in a dissolved state to the hydrosphere (e.g., [5,6]). The permafrost-carbon coupling is recognized as potentially the largest positive terrestrial feedback to anthropogenic climate change. Nevertheless, significant knowledge gaps remain concerning the quantification of the impact of thawing ground on the global carbon cycle (i.e., magnitude, type and timing of greenhouse gas emissions, e.g., [7]). Soil moisture plays a key role in determining the rate of soil carbon cycling and the type of carbon emission (e.g., $[7,8])$. Hence, there is a strong need to monitor hydrologic states and water redistribution processes in these regions, where pronounced organic surface horizons are common standard (a soil horizon is a layer whose physical characteristics differ from the layers above and beneath).

Space-borne remote sensing techniques are the only means to acquire such observations at high temporal resolution and with complete spatial coverage. The Soil Moisture and Ocean Salinity (SMOS) satellite $[9,10]$ was the first space mission to be launched (November 2009) with the objective of soil moisture observations. It carries a passive L-band microwave $(1.4 \mathrm{GHz})$ radiometer, on board. These lowest microwave frequency measurements presently available from space are considered as most suited for satellite soil moisture retrieval due to the absence of day-light and cloud restrictions, smallest surface roughness and vegetation impacts, and largest emission depths [11]. Two space missions using the same microwave band but differing technologies followed closely: Aquarius aboard the Argentine SAC-D spacecraft [12] operational between June 2011 and June 2015 as well as the Soil Moisture Active Passive (SMAP) mission launched in January 2015 [13]. From the global L-band brightness temperatures (TB) acquired by these space-borne sensors, moisture content of the soil surface layer $(\sim 0-5 \mathrm{~cm}$ depth) can be retrieved, taking advantage of the very large difference between the relative permittivity (also referred to as dielectric constant, $\varepsilon$ ) of dry soil and liquid water. Spatial resolutions are of around $\sim 40-50 \mathrm{~km}$ in case of the SMOS and SMAP missions, and $\sim 75-150 \mathrm{~km}$ in case of Aquarius, with temporal repeat cycles of 2-3 and 7 days, respectively.

The SMOS and SMAP soil moisture retrieval algorithms are based on the inversion of radiative transfer equations $[14,15]$. In these radiative transfer forward models, a dielectric model is used to relate an initial soil moisture guess to the soil's relative permittivity using auxiliary information such as soil texture, bulk density, and temperature. In the SMOS soil moisture algorithm first the Dobson model [16] using the formulation by Peplinksi et al. [17] was used. In April 2012 it was substituted with the one by Mironov et al. [18-20] and Mironov and Fomin [21] as the latter is more physically-based, offers a wider soil texture calibration range up to $100 \%$ sand, requires less auxiliary input that is often hardly available and error-prone on a global scale, as well as better numerical stability [22,23]. For the generation of the SMAP retrieval algorithm this choice was followed, supported by studies at local scale [24,25]. While the well-established Mironov and Dobson models differ in their concepts, they were both designed for application in purely mineral soils.

The structural characteristics of the above-mentioned organic surface horizons are differing from the ones of mineral soils. Organic material exhibits complex structures, small bulk densities, high porosities and large specific surface areas, leading to extreme water holding capacities up to $0.8-0.9 \mathrm{~cm}^{3} / \mathrm{cm}^{3}$ compared to around $0.4-0.6 \mathrm{~cm}^{3} / \mathrm{cm}^{3}$ in common mineral soils (e.g., [26,27]) as well as a higher fraction of bound water. During the application of an electric field, water molecules close to solid surfaces are rotationally hindered due to the active binding forces, resulting in considerably smaller relative permittivity of bound water compared to the one of free water (e.g., [28]). The dielectric characteristics of bound water in soils resemble the one of water in solid state where the molecules are bound in the rigid ice structure. Consequently, at a given water content the bulk relative permittivity 
of organic substrates with large specific surface areas is reduced compared to the one of mineral soils (with the exception of very clayey soils).

To the knowledge of the authors, thus far, only few dielectric models exist for the above-mentioned organic substrates. Mironov et al. [29] developed one temperature-dependent model valid throughout the 1 to $16 \mathrm{GHz}$ frequency range that was likewise based on the generalized refractive mixing dielectric model (GRMDM) as their above-mentioned version for mineral soils used in the SMOS and SMAP retrieval algorithms. They fit their physically-based model to relative permittivity measurements conducted on an organic tundra soil collected from the Alaska North Slope near Toolik. Recently, this model was reduced to only one frequency $(1.4 \mathrm{GHz})$ and to cover the full temperature range from 25 to $-30{ }^{\circ} \mathrm{C}$ [30]. Concurrently, Mironov and Savin [31] developed a multi-relaxation spectroscopic dielectric model (MRSDM) valid in the frequency range of $0.05-15 \mathrm{GHz}$ and from 25 to $-30{ }^{\circ} \mathrm{C}$. This model was fit to dielectric measurements using an organic tundra soil sample collected from the Siberian Yamal Peninsula. While the development of such models is without question of need, the application of the above-described Mironov et al. models for organic substrates in satellite data retrieval algorithms might be problematic at this stage. This is acknowledged by the authors themselves, who state that each model was solely built and validated on soil samples from one specific region. Furthermore, these models are not calibrated over the full wetness range, and for the laboratory measurements the material was packed to significantly higher constant bulk densities as measured in situ, while the dry bulk density of the organic soil is required as model input. In addition, this quantity is not available at global scale.

All the above motivated the ESA project "SMOSHiLat" [32] whose overall aim was to improve our understanding of L-band emission of organic soil surface layers and thus, enhance the quality of SMOS soil moisture data in the higher Northern latitudes. In the scope of SMOSHiLat different samples from organic soil surface layers were collected from various sites in Denmark, Finland, Scotland and Siberia, spanning a wide range of humus (soil organic substrate) types. On all collected samples relative permittivity measurements were carried out directly at the L-band frequency, expected to give a comprehensive insight into the sensitivity of L-band relative permittivity and thus, emission behavior of soil organic matter. Where available, measurements of samples from the underlying sandy mineral A-horizons (topmost mineral soil layer) were also considered in order to demonstrate the above-mentioned bound water effect of the organic material. These datasets are described in this paper in detail. In addition, we show simple empirical models for organic soil surface layers as well as sandy mineral soils that could be developed based on the acquired water content-relative permittivity couples. We then make use of these measured datasets and derived simple models to evaluate the above-described dielectric models for organic substrates developed by Mironov et al. [30] and Mironov and Savin [31] including cross-comparison with corresponding simulations using the Dobson et al. 1985 [16] and Mironov et al. [18-20]/Mironov and Fomin [21] dielectric models for mineral soils. The study sites and collected soil samples as well as the applied methods (for resonant cavity measurements, derivation of simple models and evaluation of existing dielectric models) are provided in Section 2. Section 3 presents the results, followed by a discussion in Section 4. Section 5 provides a summary and conclusive remarks on the presented work.

\section{Materials and Methods}

\subsection{Description of Study Sites and Soil Samples}

In Denmark, samples were collected in the Skjern River catchment in the framework of the Danish Center for Hydrology (HOBE, [33]). The naturally occurring soil type is a podsol of coarse sandy texture with pronounced organic surface layers. Within the Gludsted spruce plantation $\left(56.074^{\circ} \mathrm{N}\right.$, $9.334^{\circ} \mathrm{E}$ ) samples from organic surface horizons were taken in forested parts as well as from heathland. In case of the latter, the underlying mineral A-horizon with a considerable amount of intermixed organic material was sampled as well. In order to include a reference from the mineral A-horizon of 
low organic matter content, a sample from soil moisture and temperature network station 2.5 near the village of Brande $\left(55.9763^{\circ} \mathrm{N}, 9.0967^{\circ} \mathrm{E}\right)$ was added. This station is situated in cropland without presence of a pronounced organic layer and represents average soil texture conditions of all 30 network stations deployed within the SMOS pixel chosen for validation purposes [34].

In Finland, the samples were collected at the Finnish Meteorological Institute's Arctic Research Center (FMI-ARC) close to Sodankylä $\left(67.368^{\circ} \mathrm{N}, 26.633^{\circ} \mathrm{E}\right)$. This site is located in a typical Northern boreal forest/taiga environment with bogs prevalent under the forest canopy as well as in open terrain. Podzolized sandy-loamy glacial till deposits sometimes showing gleyic features and in most cases with pronounced organic surface layers are intermixed with peatlands [35]. The samples used in this study were extracted in a coniferous forest as well as in heathland located within a forest clearing with pronounced/thin organic surface layers, respectively. In both cases, samples were also excavated from the underlying sandy A-horizon.

In Scotland, the Centre d'Etudes Spatiales de la Biosphère (CESBIO), Toulouse, collected peat samples in two neighboring bogs on the Island Islay west of the main land $\left(55.743^{\circ} \mathrm{N}, 6.178^{\circ} \mathrm{W}\right)$.

Additionally, the Laboratoire d'Etudes en Géophysique et Océanographie Spatiales (LEGOS), Toulouse, provided organic samples taken on the West Siberian Plain during their field campaigns from a tundra area in summer $2012\left(65.910^{\circ} \mathrm{N}, 74.659^{\circ} \mathrm{E}\right)$, and a coniferous forest $\left(58.381^{\circ} \mathrm{N}, 80.664^{\circ} \mathrm{E}\right)$ as well as a bog area $\left(56.941^{\circ} \mathrm{N}, 82.607^{\circ} \mathrm{E}\right)$ in summer 2013.

All mineral and organic samples are listed in Table 1, where their main characteristics are detailed. The material collected from organic surface horizons is classified after the European Humus Forms Reference Base [36] including the samples' water regimes, humus forms and biotypes. This information is provided to demonstrate that a wide range of different types of organic substrate from both terrestrial and semi-terrestrial water regimes (never/rarely and frequently water-saturated, respectively) are covered by this study. Soil dry bulk densities as estimated from as undisturbed material as possible range $0.13-0.81$ and $1.0-1.55 \mathrm{~g} / \mathrm{cm}^{3}$ for the organic and mineral samples, respectively. Sand is the largest textural fraction (exceeding $80 \%$ ) in the studied mineral soils (determined using standard procedures, i.e., sieving and Malvern Mastersizer 2000). A rough estimate of organic matter content was obtained using the commonly used loss-on-ignition technique $\left(550{ }^{\circ} \mathrm{C}\right.$ during $\left.5 \mathrm{~h}\right)$. For the acid sandy podzol soils under consideration in this study, where carbonates, clay minerals and elemental $\mathrm{C}$ are mainly absent, the residue on ignition is considered to be closely correlated to the organic matter $[37,38]$. From Table 1 one can see the wide range of organic matter contents covered by the collected samples as well as the clear difference between organic versus mineral soil horizons. 
Table 1. Overview of the samples used for L-band permittivity measurements collected from organic and mineral horizons: Sample name, location, land cover and layer depth of sample collection. Soil properties include organic matter (OM) and texture contents and dry bulk density. Classification after the European Humus Forms Reference Base [36] includes information on the water regime (terrestrial T or semi-terrestrial ST) as well as form and biotype. Volumetric moisture content $\theta$ ranges (rounded to $0.05 \mathrm{~cm}^{3} / \mathrm{cm}^{3}$ ) of the data available after filtering are also indicated.

\begin{tabular}{|c|c|c|c|c|c|c|c|c|c|c|c|}
\hline Type & Sample Name & Location & $\begin{array}{l}\text { Land } \\
\text { Cover }\end{array}$ & $\begin{array}{l}\text { Layer Depth } \\
\text { (cm) }\end{array}$ & $\begin{array}{l}\text { OM } \\
(\%)\end{array}$ & $\begin{array}{c}\text { Sand/Silt/Clay } \\
(\%)\end{array}$ & $\begin{array}{l}\text { Density } \\
\left(\mathrm{g} / \mathrm{cm}^{3}\right)\end{array}$ & $\begin{array}{l}\text { Water } \\
\text { Regime }\end{array}$ & $\begin{array}{l}\text { Form and } \\
\text { Biotype }\end{array}$ & Horizons & $\begin{array}{c}\theta \text { Range } \\
\left(\mathrm{cm}^{3} / \mathrm{cm}^{3}\right)\end{array}$ \\
\hline \multirow{12}{*}{ Organic } & FMI_Spruce_2013_O & Sodankylä, FI & Forest & $0-5$ & 89.73 & & 0.13 & $\mathrm{~T}$ & Terro Mor & OF & Excluded \\
\hline & FMI_Elbara_2013_O & Sodankylä, FI & Heath & $0-3$ & 51.27 & & 0.28 & $\mathrm{~T}$ & Enti Mor & OL-OF-OH & $0.00-0.75$ \\
\hline & HOBE_heath_2013_O1 & Gludsted, DK & Heath & $0-4$ & 91.22 & & 0.18 & $\mathrm{~T}$ & Terro Moder & OL-OF & $0.00-0.85$ \\
\hline & HOBE_heath_2013_O2 & Gludsted, DK & Heath & $4-6$ & 64.95 & & 0.81 & $\mathrm{~T}$ & Terro Moder & $\mathrm{OH}$ & $0.10-0.80$ \\
\hline & HOBE_forest_2013_O1 & Gludsted, DK & Forest & $0-4$ & 83.19 & & 0.16 & $\mathrm{~T}$ & Terro Mor & OL-OF & $0.00-0.85$ \\
\hline & HOBE_forest_2013_O2 & Gludsted, DK & Forest & $4-10$ & 22.27 & & 0.79 & $\mathrm{~T}$ & Terro Mor & $\mathrm{OH}$ & $0.05-0.65^{1}$ \\
\hline & Islay_peat1_2013_O1 & Islay, GB & Bog & $0-5$ & 95.22 & & 0.04 & ST & Histo Mor & hf & $0.00-0.60^{2}$ \\
\hline & Islay_peat1_2013_O2 & Islay, GB & Bog & 5-10 & 91.65 & & 0.12 & ST & Histo Mor & $\mathrm{hm}$ & $0.00-0.45$ \\
\hline & Islay_peat2_2013_O & Islay, GB & Bog & $0-10$ & 95.65 & & 0.24 & ST & Histo Mor & hf(-hm) & $0.00-0.80$ \\
\hline & siberia_tundra_2012_O & Siberia, RU & Tundra & $0-10$ & 95.23 & & 0.13 & ST & Hydro Mor & (OLg)-OFg-(OHg) & $0.00-0.85$ \\
\hline & siberia_bog_2013_O & Siberia, RU & Bog & $0-10$ & 97.98 & & 0.03 & ST & Histo Mor & $\mathrm{hf}$ & $0.00-0.70$ \\
\hline & siberia_forest_2013_O & Siberia, RU & Forest & $0-10$ & 72.98 & & 0.1 & $\mathrm{~T}$ & Terro Mor & OL-OF-OH & $0.00-0.60$ \\
\hline \multirow[t]{5}{*}{ Mineral } & FMI_Spruce_2013_S & Sodankylä, FI & Forest & $10-15$ & 9.44 & $84.8 / 0.2 / 0.0$ & 1.06 & & & $\mathrm{OH}-\mathrm{A}$ & $0.00-0.40$ \\
\hline & FMI_Elbara_2013_S1 & Sodankylä, FI & Heath & $3-6$ & 3.78 & $91.5 / 1.4 / 0.3$ & 1.00 & & & A & $0.00-0.15$ \\
\hline & FMI_Elbara_2013_S2 & Sodankylä, FI & Heath & $6-12$ & 3.66 & $92.4 / 2.6 / 0.0$ & 1.50 & & & A & $0.00-0.35$ \\
\hline & HOBE_heath_2013_S & Gludsted, DK & Heath & $6-12$ & 10.69 & $84.7 / 13.9 / 1.4$ & 1.26 & & & OH-A & $0.10-0.50$ \\
\hline & HOBE_nw_avg_S $\bar{S}$ & Brande, DK & Cropland & $0-5$ & 4.86 & $87.3 / 7.3 / 4.9$ & 1.22 & & & A & $0.00-0.30$ \\
\hline
\end{tabular}

Exluded values: ${ }^{1} 0.25$ and ${ }^{2} 0.55,0.40$. 


\subsection{Resonant Cavity Using Weak Perturbation Method}

The L-band relative permittivity measurements were carried out at the Laboratoire de l'Intégration du Matériau au Système (University of Bordeaux, France). The weak perturbation method [39] was applied using a rectangular resonant cavity with dimensions $16.5 \mathrm{~cm} \times 8.2 \mathrm{~cm} \times 51.4 \mathrm{~cm}$ (width $\times$ height $\times$ length) closed at each extremity by a short circuit, as also described in Demontoux et al. [40] and illustrated in Figure 1a. The cavity has two antennas placed at a quarter wavelength of each short circuit in order to generate a stationary wave within the empty cavity at a specific resonant frequency. These input (1) and output (2) ports are connected to a vector network analyser (VNA, ANRITSU 37325A) by coaxial cables. The latter introduce a time delay, causing phase shift as well as some attenuation. To correct for these systematic errors a standard calibration procedure is applied prior to any measurements. The VNA permits the recording of the network's four complex S-parameters (scattering matrix), expressing the relationship between the reflected and incident power waves at the network ports 1 and 2, whereby: S11 and S12 indicate the reflection and backward transmission at the input port, S21 and S22 the forward transmission and reflection at the output port, respectively. Different resonant frequencies linked to the cavity dimensions can be applied. In our case, all measurements were performed at $1.26 \mathrm{GHz}$ where the magnitude of the electric field at the cavity center is at its maximum resulting in high sensitivity. From the resonant frequency $\mathrm{f}$ the quality factor $\mathrm{Q}$ can be defined as follows:

$$
\mathrm{f}=\sqrt{ }\left((\mathrm{c} / 2)\left[\left(\mathrm{m}^{2} / \mathrm{a}\right)+\left(\mathrm{n}^{2} / \mathrm{b}\right)+\left(\mathrm{p}^{2} / \mathrm{l}\right)\right]\right),
$$

with the speed of light $c$, the width $a$, height $b$ and length 1 of the cavity, and the numbers of half wavelength variations of the electric field in the width $\mathrm{m}$, height $\mathrm{n}$ and length $\mathrm{p}$ directions, respectively.

$$
Q=2 \pi f(W /(W / d t)),
$$

where "W/(W/dt)" denotes the energy stored in the cavity divided by the energy dissipated per cycle. Note that the dissipation of energy occurs mainly in the sample introduced into the resonant cavity.

When introducing a sample-filled glass tube at the center of the cavity, one can observe the changes in the resonance parameters $f$ and $Q$ directly obtained from the measured complex S21 coefficient. As these changes are mainly a function of the sample's relative permittivity $\varepsilon$, one can then infer the real $\left(\varepsilon^{\prime}\right)$ and imaginary $\left(\varepsilon^{\prime \prime}\right)$ part of the latter as following:

$$
\begin{gathered}
\varepsilon^{\prime}=1+(1 / \alpha)^{*}\left(\left(\mathrm{f}_{0}-\mathrm{f}_{1}\right) / \mathrm{f}_{0}\right) \\
\varepsilon^{\prime \prime}=(1 / 2 \alpha)^{*}\left(\left(1 / \mathrm{Q}_{1}\right)-\left(1 / \mathrm{Q}_{0}\right)\right)
\end{gathered}
$$

where $\alpha$ is the filling factor, while " 0 " and " 1 " denote empty and sample-filled glass tubes, respectively.

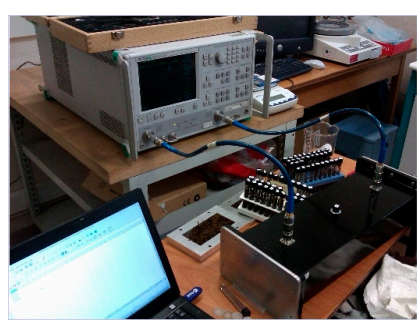

(a)

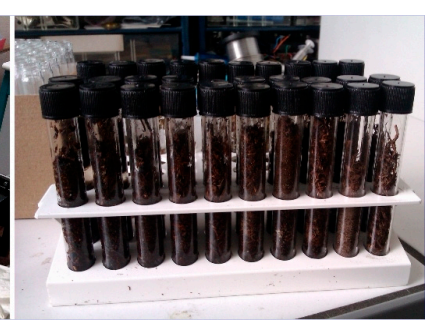

(b)

Figure 1. (a) Rectangular resonant cavity with a sample in a glass tube inserted in the center, connected to vector network analyzer (ANRITSU 37325A) by means of two coaxial cables; (b) glass tubes filled with samples of organic material at different wetness contents.

When the glass tube covers the entire cavity height, the filling factor can be approximated by $\alpha=2^{*}$ sample volume/cavity volume. However, tubes filled with soil samples at high water contents 
dampened the transmitted electromagnetic wave to an extent rendering measurements impossible. Since we did not want to lose any of the already limited sample thickness, and thus, degree of sample heterogeneity, we decided not to reduce the tubes' diameter (inner diameter of $10 \mathrm{~mm}$ ) but rather to adjust their length inserted into the cavity to $4 \mathrm{~cm}$ depth, resulting in a sample volume of $5.2 \mathrm{~cm}^{3}$. This necessitated specific calibration of the filling factor $\alpha$ as explained in the following.

\subsection{1. $\alpha$-Factor Calibration for Adjusted Tube Length}

We first prepared 11 water and acetic acid mixtures in order to obtain standard liquids with different relative permittivities, spanning the range from $100 \%$ water (sample 1 ) to $100 \%$ acetic acid (sample 11). These were filled into especially slim glass tubes (with an inner diameter of $3 \mathrm{~mm}$ ), that could be inserted into the resonant cavity at their full length without too much disturbing the wave transmission. Using the well-known permittivity values of water at $1.26 \mathrm{GHz}\left(\varepsilon^{\prime} / \varepsilon^{\prime \prime}{ }_{\text {water }}=77 / 5.75\right)$ together with empty glass tube measurements $f_{0}-Q_{0}$ as well as water-filled tube measurements $\left(f_{1}-Q_{1}\right), \alpha$ values were calculated for the real and imaginary part $\left(\alpha^{\prime} / \alpha^{\prime \prime}\right)$ using Equations (3) and (4), respectively. Next, the resonance parameters $\mathrm{f}$ and $\mathrm{Q}$ of the slim glass tubes containing the 11 mixtures were measured. Together with the previously calculated $\alpha$ values, $\varepsilon^{\prime} / \varepsilon^{\prime \prime}$ were then computed for each water-acetic acid sample (Figure 2a). The same samples in ordinary glass tubes (as used for the measurements of our soil samples) were then inserted into the resonant cavity in order to obtain $\mathrm{f}$ and $Q$ for the sample depth of $4 \mathrm{~cm}$. Using these measurements together with the "slim tube" $\varepsilon^{\prime} / \varepsilon^{\prime \prime}$ estimates, $\alpha^{\prime} / \alpha^{\prime \prime}$ values for each water-acetic acid mixture were derived. Figure $2 b$, c, show the resonant frequency and the quality factor for the 11 samples and the $4 \mathrm{~cm}$ depth plotted against respective real and imaginary alpha values. Thanks to the relation between $\varepsilon^{\prime}$ and varying water-acetic acid fractions, covering the entire permittivity range from 80 for pure water (sample 1) to almost 1 for pure acetic acid (sample 11) a third order polynomial could be fit through the $\mathrm{f}-\alpha^{\prime}$ couples. Concerning the imaginary part, such a precise alpha calibration was not possible by means of this dataset-the explicit $\varepsilon^{\prime \prime}$-water-acetic acid fraction relation was not existant like for $\varepsilon^{\prime}$, and the range of quality factors obtained from our 11 samples was not covering the full range of Qs measured for our organic samples. However, since the $\alpha^{\prime \prime}$ values of the 11 mixtures did not vary substantially, we used the mean value. This approximation is not expected to translate large errors into the L-band emission modeling since $\varepsilon^{\prime}$ has generally a much larger impact than $\varepsilon^{\prime \prime}$.

(a)

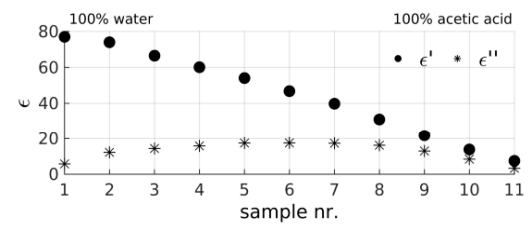

(b)
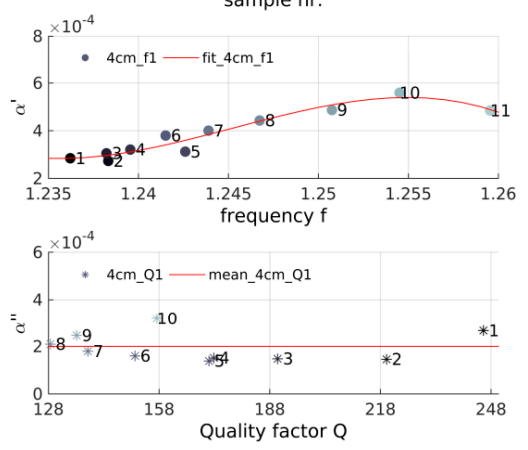

Figure 2. (a) Filling factor $\alpha$ calibration using mixtures spanning the range from $100 \%$ water (sample 1 ) to $100 \%$ acetic acid (sample 11 ): Permittivity real and imaginary part $\varepsilon^{\prime} / \varepsilon^{\prime \prime}$ computed for slim glass tubes filled with water-acetic acid sample inserted into cavity at full lenght; (b) resonant frequency $\mathrm{f}$ and (c) Quality factor Q plotted against $\alpha^{\prime} / \alpha^{\prime \prime}$ values derived for each water-acetic acid mixture and the $4 \mathrm{~cm}$ tube depths including the $3 \mathrm{rd}$ order polynomial fit/mean value, respectively. 


\subsubsection{Sample Preparation}

The soil samples collected from terrestrial water regimes (see Table 1) were oven dried at $105{ }^{\circ} \mathrm{C}$ for $24 \mathrm{~h}$ and at $85^{\circ} \mathrm{C}$ for $48 \mathrm{~h}$ in case of mineral and organic materials, respectively. The latter is based on results by $\mathrm{O}^{\prime}$ Kelly [41] who had found that around this temperature, mass loss due to charring balanced the effects of residual water caused by the strong water-binding capacities of organic matter. The dried material was filled into the glass tubes using pre-defined dry bulk densities (see Section 2.1 and Table 1). Different amounts of water were added with a pipette in order to obtain volumetric water contents spanning the entire wetness range from fully dry to saturated stage, with two tubes per step. The effective water content added was then calculated by the gravimetric water content (i.e., (mass after water added in tube-dry mass)/tube volume). A photo of the prepared glass tube samples is shown in Figure $1 b$.

Organic substrates can be affected by shrinkage during drying (e.g., [42,43]), meaning that the bulk density can change as a function of water content. A precedent drying test showed that some shrinkage mainly occured for the semi-terrestrial organic substrate types (i.e., Scottish bog as well as Siberian bog and tundra samples, Table 1). Therefore, the material of these samples was initially saturated in order to automatically account for the changing volume and bulk density during the subsequent dry down. The saturated bulk densities of the respective soils were previously estimated and two glass tubes were filled. Then, the soil was progressively oven-dried and from time to time some material was filled into two glass tubes per step according to respective bulk densities until the point where no further mass loss occurred. With respect to these wet bulk densities, they were calculated from samples taken at some water content steps (using cylinders of known volume), while in between interpolated values were used. The water content was estimated after the resonant cavity measurements by oven-drying for estimation of the gravimetric moisture content and conversion into volumetric moisture content by the knowledge of the respective dry bulk densities. This very labor intensive approach in order to take shrinkage effects into account, also bears some drawbacks. To mention are the assumptions made in the estimation of the wet bulk densities or some material possibly lost during the removal of samples from the glass tubes for the determination of the respective water contents. For these reasons, it is finally unclear whether this sampling procedure is actually more accurate than mixing the dry material and the water directly in the glass tubes. However, what is most important here, and as will be shown in Section 3, it does yield valid results.

\subsubsection{Measurement Procedure and Data Processing}

At the beginning of each operation an empty glass sample was measured as reference $\left(f_{0} / Q_{0}\right)$. Then, each tube was measured three times at room temperature, whereupon the specifically calibrated alpha values together with our soil measurements $f$ and $Q$ (average of the three repetitions) were used to calculate $\varepsilon^{\prime} / \varepsilon^{\prime \prime}$ (Equations (3) and (4)) for each sample and water content. The obtained $\varepsilon^{\prime} / \varepsilon^{\prime \prime}$ values were subsequently averaged based on water content bins of maximum $0.05 \mathrm{~cm}^{3} / \mathrm{cm}^{3}$ range. All raw data ( $f$ and $Q$ ) and the derived relative permittivities were quality checked and some data had to be filtered as described in the following: The relative permittivity estimates of the FMI Spruce organic sample ("FMI_Spruce_2013_O") were excluded as they were clearly offset compared to the measurements of all other organic samples. A systematic measurement error was assumed (measurements possibly carried out with only $3 \mathrm{~cm}$ tube depth inserted into the resonant cavity). Additionally, the previously estimated dry soil bulk density had to be lowered during sample preparation. As the "FMI_Spruce_2013_O" was the only sample where this problem occurred, we believe that we must have made a mistake during the sampling procedure for the estimation of the bulk density. Few other clear outliers were removed, in most cases samples where saturation had been reached with standing water building inside of the tube resulting in an unexpected decrease of $\varepsilon$ (e.g., “HOBE_nw_avg_S”, “FMI_Elbara_2013_O”, “FMI_Elbara_2013_S2", “FMI_Spruce_2013_S”, "Islay_peat1_2013_O2"). In other cases, bad sample preparation and/or measurement mistakes (e.g., “FMI_Elbara_2013_S1", “HOBE_forest_2013_O2", “Islay_peat1_2013_O1”, room temperature) were 
also very likely to be the cause. As an example, deviation from the vertical position of the samples introduced to the cavity can introduce errors. Table 1 shows the accepted water content ranges (after filtering) of the measurements conducted at room temperature.

\subsection{Derivation of Simple Empirical Models and Evaluation of Existing Dielectric Models}

Careful analysis of the resonant cavity measurements showed the dataset's potential to derive simple empirical models for organic and sandy mineral substrates by fitting 3rd order polynomials through the respective relative permittivity-water content couples. We then made use of these measured datasets and derived simple dielectric models to evaluate existing dielectric models. The data measured on organic samples and the corresponding model were compared to the two dielectric models by Mironov et al. [30] and Mironov and Savin [31] for organic substrates. As we did not have the actual model codes, water content-relative permittivity couples modeled at the $1.4 \mathrm{GHz}$ frequency were adopted from the two papers. The gravimetric water content reported in Mironov and Savin [31] was converted to volumetric water content applying a bulk density of $0.795 \mathrm{~g} / \mathrm{cm}^{3}$, as used on average by the authors for the lab measurements. Then, 2 nd order polynomials were fit through the two model datasets for easier comparison. In case of the Mironov et al. [30] model the values at $20^{\circ} \mathrm{C}$ were extracted (corresponding to room temperature), while in Mironov and Savin [31] the presented values estimated at $10{ }^{\circ} \mathrm{C}$ were used. As shown by Mironov et al. [30] the change between $\varepsilon$ at 10 and $20^{\circ} \mathrm{C}$ is marginal so that this comparison should hold. The data ranges that we could adopt from the information presented in literature reached up to water contents of 0.536 and $0.411 \mathrm{~cm}^{3} / \mathrm{cm}^{3}$ in case of Mironov et al. [30] and Mironov and Savin [31] while at the same time the authors stated that the actual model calibration ranges go up to approximately 0.573 and $0.55 \mathrm{~cm}^{3} / \mathrm{cm}^{3}$, respectively. However, this does not influence the overall conclusions of our paper as will be discussed in Section 4.2. The data measured on mineral samples and the corresponding simple model only account for the sandy soil fraction, and thus, are not generally applicable throughout the full texture range of mineral soils. Here they were included to (1) cross-compare the relative permittivities estimated from organic samples with the ones of the underlying sandy mineral soils; and to (2) cross-check our measurements against well-established dielectric models, namely, the Dobson et al. [16] and Mironov et al. [18-20]/Mironov and Fomin [21] dielectric models for mineral soils (in the following referred to as Dobson and Mironov mineral model, respectively). The latter models were run at $20^{\circ} \mathrm{C}$ (room temperature) and using average soil properties as encountered in the mineral soil samples used for the resonant cavity measurements (Table 2). Pearson's correlation coefficients (R), bias (mean difference between expected and measured values), and bias-corrected root mean square deviations (UbRMSD) were computed between measured data and all above-mentioned dielectric models for organic and mineral cases, respectively.

Table 2. Parameters chosen for dielectric modeling using the Dobson and Mironov mineral models, respectively, together with average soil properties as encountered in the mineral soil samples used for the resonant cavity measurements.

\begin{tabular}{cccc}
\hline Parameter & Description & Dobson Mineral Model & Mironov Mineral Model \\
\hline $\mathrm{T}\left({ }^{\circ} \mathrm{C}\right)$ & Temperature & 20 & 20 \\
Sand $(\%)$ & Sand fraction & 88 & - \\
Clay $(\%)$ & Clay fraction & 1.3 & 1.3 \\
Rhob $\left(\mathrm{g} / \mathrm{cm}^{3}\right)$ & Dry soil bulk density & 1.27 & - \\
Rhos $\left(\mathrm{g} / \mathrm{cm}^{3}\right)$ & Dry solid soil particle density & 2.66 & - \\
\hline
\end{tabular}

\section{Results}

Figure 3 shows all average resonant cavity permittivity estimates (real and imaginary parts in left and right panel, respectively) of samples from organic horizons at room temperature for the entire 
wetness range and filtered as specified in Section 2.2.3, in grey when using an alpha filling factor for the full tube length and in red specifically calibrated for the $4 \mathrm{~cm}$ tube insertion depth.

Figure 4 illustrates the filtered average resonant cavity measurements of relative permittivity (real and imaginary parts) over the entire wetness range and at room temperature with different colors for individual (a) mineral and (b) organic samples (shades of blue and yellow-red-purple, respectively, see Table 1). The simple empirical models (3rd order polynomials) fit through the cavity datasets obtained from mineral and organic samples are plotted along in Figure 4a,b, respectively (blue and red lines). The corresponding model coefficients are listed in Table 3. Respective statistics are provided in Table 4.
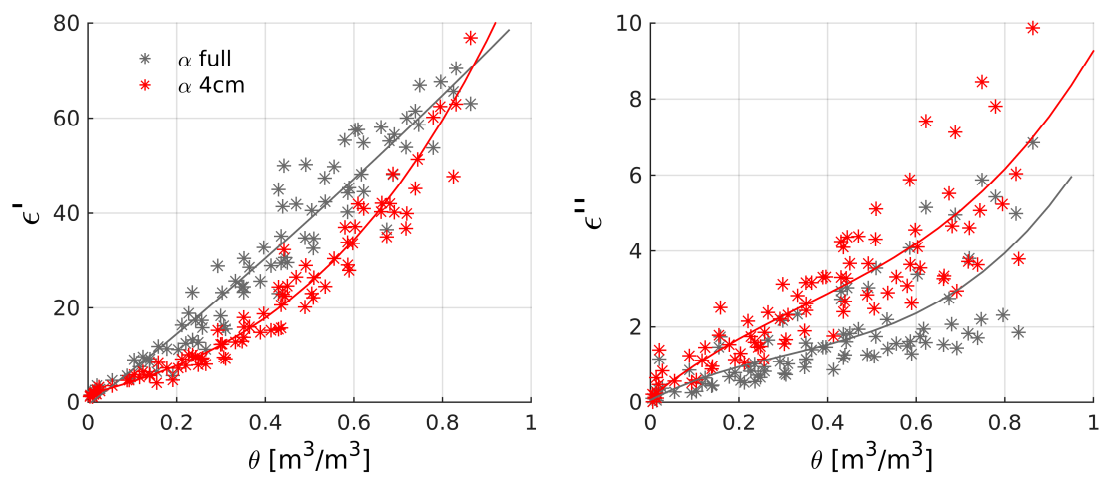

Figure 3. Estimated permittivities, (a) real $\varepsilon^{\prime}$ and (b) imaginary $\varepsilon^{\prime \prime}$ part, of all organic samples measured over the entire wetness range $\theta$ and at room temperature (filtered as specified in Section 2.2.3), using a filling factor $\alpha$ for the full tube length (grey) and specifically calibrated for the $4 \mathrm{~cm}$ tube insertion depth (red).

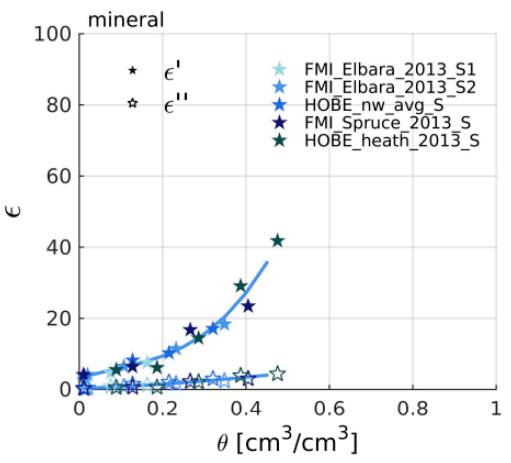

(a)

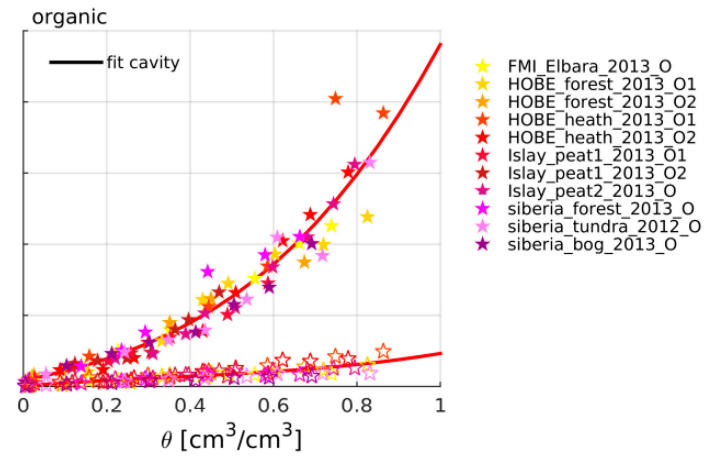

(b)

Figure 4. Average resonant cavity relative permittivity $\varepsilon$ measurements (filled and empty stars for real $\varepsilon^{\prime}$ and imaginary $\varepsilon^{\prime \prime}$ part, respectively) over the entire wetness range $\theta$, at room temperature, for the (a) individual mineral and (b) organic samples. Simple empirical models fit through the cavity datasets of all organic and mineral samples (for $\varepsilon^{\prime}$ and $\varepsilon^{\prime \prime}$, respectively) are plotted along (solid line).

Table 3. Coefficients of the simple model for organic substrates and for sandy mineral soils, respectively: third order polynomial functions through the water content-relative permittivity (real $\varepsilon^{\prime}$ and imaginary $\varepsilon^{\prime \prime}$ part) couples of all available organic/mineral samples (see Table 1 ) measured by means of the resonant cavity method, with fit_organic(x)/fit_mineral $(x)=c 1^{*} \times{ }^{\wedge} 3+c 2^{*} \times{ }^{\wedge} 2+c 3^{*} \times+c 4$.

\begin{tabular}{cccccc}
\hline Type & & c1 & c2 & c3 & c4 \\
\hline \multirow{2}{*}{ Organic } & $\varepsilon^{\prime}$ & 50.69 & 18.81 & 25 & 1.636 \\
& $\varepsilon^{\prime \prime}$ & 10.61 & -11.08 & 9.613 & 0.1211 \\
\hline \multirow{2}{*}{ Mineral } & $\varepsilon^{\prime}$ & 404.3 & -98.4 & 34.54 & 3.183 \\
& $\varepsilon^{\prime \prime}$ & -7.946 & 14.51 & 3.29 & 0.3185 \\
\hline
\end{tabular}


In Figure 5a our simple empirical model for sandy mineral soils (light blue stars) is depicted (real and imaginary parts in top and bottom panel, respectively) together with the outputs of the Dobson and Mironov mineral model runs (blue and dark blue circles, respectively), with input corresponding to average conditions encountered in the mineral soil samples used for our measurements (Table 2). These models' calibration ranges are denoted by filled icons. For cross-comparison, the simple empirical model for organic substrates (red stars) is also included here. Figure 5b illustrates again our empirical model for organic substrates, now together with the functions fit through the output of the two dielectric models for organic substrates adopted from literature (Mironov et al. [30] and Mironov and Savin [31], orange and salmon triangles, respectively). The data ranges available from these references for curve fitting are denoted by filled icons. Additionally, the relative permittivity measurements obtained from all organic samples after filtering are shown (grey dots). The statistics for the comparison of the different model outputs with our cavity measurement datasets for mineral and organic substrates, respectively, are provided in Table 4.
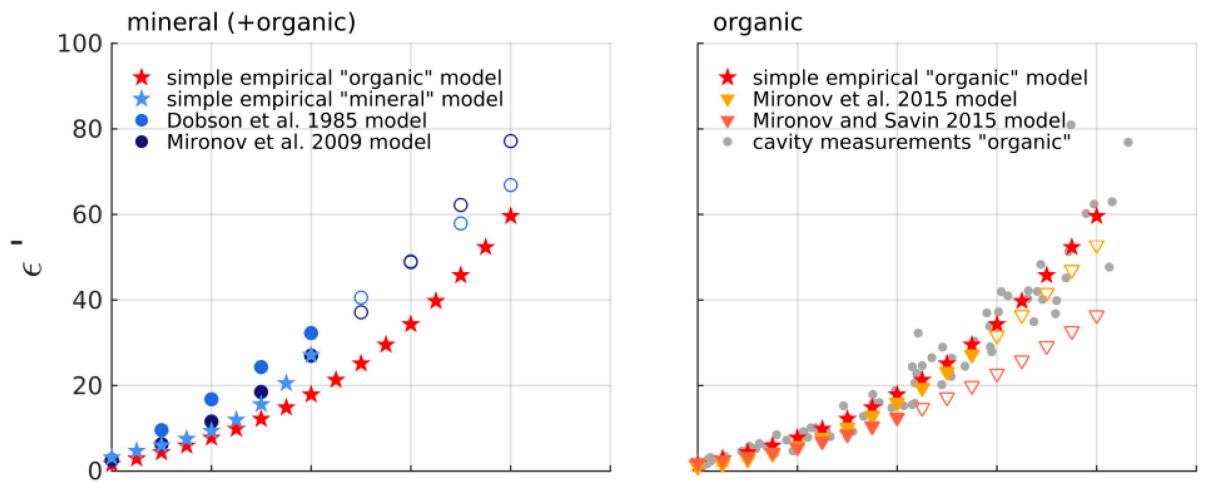

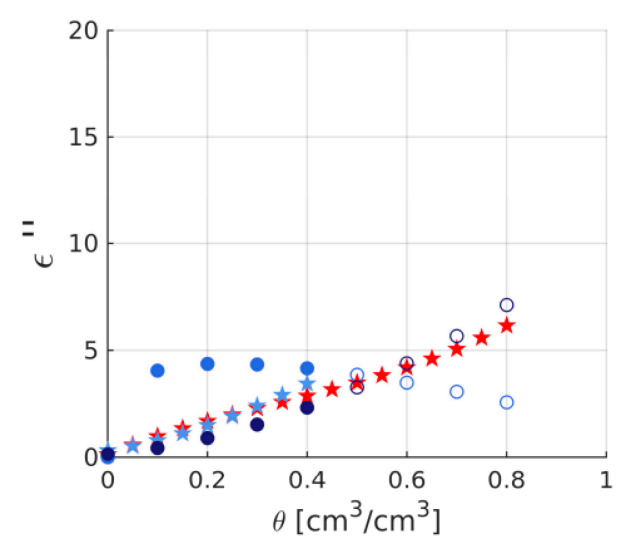

(a)

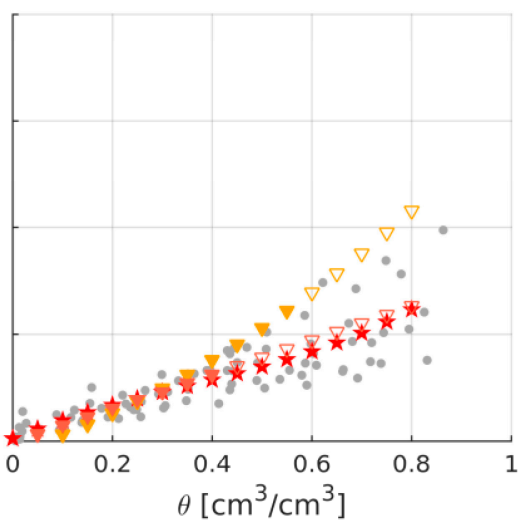

(b)

Figure 5. Measured and modeled relative permittivity data as a function of soil moisture at room temperature, real $\varepsilon^{\prime}$ (top panel) and imaginary $\varepsilon^{\prime \prime}$ (bottom panel) parts. (a) Simple empirical models based on 3rd order polynomial fits through the collectivity of sandy mineral as well as organic samples (light blue and red stars, respectively), Dobson and Mironov mineral model outputs (blue and dark blue circles, respectively) using input specificed in Table 2; (b) resonant cavity measurements acquired from all organic samples after filtering (grey dots) including the empirical model for organic substrates (red stars), now together with curves fit through output of the Mironov et al. [30] and Mironov and Savin [31] models for organic soil layers (orange and salmon triangles, respectively) adopted from literature. Filled icons denote the range where data was available for (a) model calibration of the Dobson and Mironov mineral models or (b) for curve fitting to the data presented in Mironov et al. [30] and Mironov and Savin [31]. 
Table 4. Statistics for the simple empirical models fit through the resonant cavity datasets (real $\varepsilon^{\prime}$ and imaginary $\varepsilon^{\prime \prime}$ parts of the relative permittivity) of all organic and mineral samples, respectively, as well as agreement of output of different dielectric models with the resonant cavity measurements: $\mathrm{N}=$ Number of datapoints, $\mathrm{R}=$ Pearson's correlation coefficient, Bias = mean difference between expected and measured values, UbRMSD = bias-corrected root mean square deviation.

\begin{tabular}{|c|c|c|c|c|c|c|}
\hline Type & Model & & $\mathbf{N}$ & $\mathbf{R}$ & Bias & UbRMSD \\
\hline \multirow{6}{*}{ Organic } & \multirow{2}{*}{$\begin{array}{l}\text { Simple empirical model based on } \\
\text { cavity measurements }\end{array}$} & $\varepsilon^{\prime}$ & 87 & 0.96 & $2.80 \times 10^{-15}$ & 4.8 \\
\hline & & $\varepsilon^{\prime \prime}$ & 87 & 0.86 & $5.46 \times 10^{-16}$ & 1.0 \\
\hline & \multirow{2}{*}{ Mironov et al. [30] } & $\varepsilon^{\prime}$ & 87 & 0.96 & 2.4 & 5.1 \\
\hline & & $\varepsilon^{\prime \prime}$ & 87 & 0.86 & -1.2 & 2.0 \\
\hline & \multirow{2}{*}{ Mironov and Savin [31] } & $\varepsilon^{\prime}$ & 87 & 0.96 & 7.1 & 8.4 \\
\hline & & $\varepsilon^{\prime \prime}$ & 87 & 0.86 & -0.1 & 1.0 \\
\hline \multirow{6}{*}{ Mineral } & \multirow{2}{*}{$\begin{array}{l}\text { Simple empirical model based on } \\
\text { cavity measurements }\end{array}$} & $\varepsilon^{\prime}$ & 20 & 0.98 & $-5.33 \times 10^{-15}$ & 1.8 \\
\hline & & $\varepsilon^{\prime \prime}$ & 20 & 0.96 & $7.11 \times 10^{-16}$ & 0.3 \\
\hline & \multirow{2}{*}{ Dobson et al. [16] } & $\varepsilon^{\prime}$ & 20 & 0.93 & -4.5 & 3.9 \\
\hline & & $\varepsilon^{\prime \prime}$ & 20 & 0.86 & -1.6 & 0.6 \\
\hline & Mironov et al. [18-20]// & $\varepsilon^{\prime}$ & 20 & 0.96 & -0.6 & 2.7 \\
\hline & Mironov and Fomin [21] & $\varepsilon^{\prime \prime}$ & 20 & 0.96 & 0.6 & 0.5 \\
\hline
\end{tabular}

\section{Discussion}

\subsection{Measured Resonant Cavity Dataset and Derived Simple Empirical Models}

Relative permittivity estimates obtained from resonant cavity measurements when using a default alpha filling factor accounting for the full tube length were compared with the ones computed by means of alphas calibrated for only the tube length that was inserted into the cavity (Figure 3, grey and red icons, respectively). This demonstrates the impact of an $\alpha$ that is not specifically calibrated for the actual tube length on the calculated $\varepsilon^{\prime}$ and $\varepsilon^{\prime \prime}$, and thus, the importance of this step.

Figure 4 illustrates that all relative permittivity data obtained from the resonant cavity measurements show a consistent trend with increasing values as the water content increases in case of samples from organic as well as mineral substrates (shades of yellow-red-purple and blue, respectively). Though some variability can be observed, especially in the data measured from samples of organic character, no distinct differences in behavior can be detected between the samples from different sites. With respect to the organic samples, spanning a wide range of organic substrate types from both terrestrial and semi-terrestrial water regimes and of variable organic matter contents and bulk densities, this implies that generally, a uniform dielectric response, and thus, L-band emission behavior can be expected from organic soil surface layers. These findings allowed the derivation of simple empirical models by fitting 3rd order polynomials through couples of water content and the relative permittivity's real as well as imaginary parts obtained from the resonant cavity measurements on mineral and organic samples, respectively (blue and red lines in Figure 4, the models' coefficients are listed in Table 3). The respective statistics (Table 4) reveal generally high correlation coefficients, acceptable UbRMSDs, and (as expected in case of such fits) almost non-existant biases. The UbRMSDs are larger for the relative permittivity's real and imaginary parts estimated from cavity measurements in organic substrate, conforming with the larger spread in this dataset compared to the one obtained from measurements in mineral soils.

\subsection{Evaluation of Existing Dielectric Models by Means of Measured Resonant Cavity Dataset and Derived Simple Empirical Models}

With respect to the data obtained from measurements on mineral soils, higher $\varepsilon^{\prime}$ modeled by means of the Dobson (blue circles) compared to the Mironov mineral model (dark blue circles) at a given water content are noticeable (Figure 5a, top panel). Meanwhile, our simple empirical model derived for sandy mineral soils (light blue stars) follows the respective $\varepsilon^{\prime}$ estimations by the Mironov mineral model closely though with slightly increased curvature. At the same time, the Dobson mineral 
model output shows a clearly unrealistic behavior of $\varepsilon^{\prime \prime}$ (Figure 5a, bottom panel), demonstrating the model's limitation for application in very sandy soils since it was only calibrated up to $50 \%$ sand. Again, our model lies in much closer range with the output from the Mironov mineral model. This is in agreement with the results earlier presented by Bircher et al. [24] and supports the choice of this model in the SMOS and SMAP soil moisture retrieval algorithms as suggested by Mialon et al. [23] and Srivastava et al. [25].

What stands out in the top panel of Figure 5a is the reduced real part of the relative permittivity of our simple empirical model for organic substrates (red stars) compared to the one for the underlying sandy mineral soils as well as the outputs of the Dobson and Mironov mineral models. As addressed in Section 1, this conforms with theory (e.g., [28]), in that the higher bound water fractions in organic material of complex structure and with large surface areas leads to a larger amount of rotationally hindered water molecules, and thus, reduced $\varepsilon^{\prime}$ than encountered in mineral soils. Furthermore, the here presented results agree with the findings of Bircher et al. [44] concerning respective datasets acquired by means of conventional in situ soil moisture sensors. This demonstrates the significant overestimation of $\varepsilon^{\prime}$ obtained when using the Dobson or Mironov mineral models in soil moisture retrieval forward models as used in the SMOS and SMAP algorithms over areas with organic soil surfaces. This is especially important since these differences increase with increasing moisture content together with the fact that moisture levels in organic material are usually quite high. Note that very clayey soils have similarly high bound water fractions as organic substrates. Sensitivity tests with the Mironov mineral model showed that the clay fraction had to be raised to a value as high as 0.65 in order to bring $\varepsilon^{\prime}$ in agreement with our empirical model for organic substrates (not shown), conditions not frequently met when consulting global soil texture maps (e.g., [45]).

Concurrently, our simple model derived for organic substrates is in very close agreement with the Mironov et al. [30] (orange triangles) and Mironov and Savin [31] (salmon triangles) models for organic soil horizons at low water contents. The real part of the permittivity (Figure 5b, top panel) estimated by the Mironov and Savin [31] model has a flatter curve shape, and thus, starts deviating at a moisture content of around $0.3 \mathrm{~cm}^{3} / \mathrm{cm}^{3}$. Nevertheless, it rests in proximity to our empirical model within the range where data was available for curve fitting (filled icons). This discrepancy likely arises from the fact that the data adopted from Mironov and Savin [31] only goes up to $0.411 \mathrm{~cm}^{3} / \mathrm{cm}^{3}$ while the model was actually calibrated up to $0.55 \mathrm{~cm}^{3} / \mathrm{cm}^{3}$. Therefore, this fit is not reliable in the higher wetness range and will not be considered in the further discussion. Meanwhile, the Mironov et al. [30] model run where data for the fit was available almost up to the model calibration range $(0.536$ versus $0.573 \mathrm{~cm}^{3} / \mathrm{cm}^{3}$ ) keeps following our simple model closely throughout the data fitting range and only starts slightly deviating above $\sim 0.58 \mathrm{~cm}^{3} / \mathrm{cm}^{3}$ where the calibration range of the model is left. In turn, concerning $\varepsilon^{\prime \prime}$ (Figure 5b, bottom panel), the Mironov and Savin [31] model is in closer agreement with our simple model (though, naturally the above remark on the limited fitting range is also valid here). $\varepsilon^{\prime \prime}$ modeled by means of the Mironov et al. [30] model exhibits a steeper slope compared to our simple model, with values departing at water contents of around $0.35 \mathrm{~cm}^{3} / \mathrm{cm}^{3}$. However, Mironov et al. [30] show that their model predictions overestimate the measured $\varepsilon^{\prime \prime}$ at higher water contents, possibly explaining the encountered difference. Furthermore, we also have to keep in mind that the assumptions made in the alpha factor calibration for the imaginary part (Section 2.2.1) could cause some uncertainties in the $\varepsilon^{\prime \prime}$ values estimated from our resonant cavity measurements.

All of the above said, we have to remember that the two Mironov et al. models were both generated based on samples from only one type of organic soil surface layer. The fact that outputs from both the Mironov et al. [30] and Mironov and Savin [31] dielectric models (within the wetness validity range of the fit, filled icons) lie within the spread of the L-band relative permittivity data obtained from our resonant cavity measurements on samples from various organic horizon types (grey dots) underlines the very good correspondence. It strengthens confidence in the validity of the simple as well as the more sophisticated dielectric models. The here derived simple dielectric model, considering a large variety of organic substrate types and the entire expected wetness range in the calibration 
process and not relying on globally unavailable auxiliary input data, should be generically applicable wherever organic soil surface layers are present (also in lower latitude regions). Of course, the high spread in the resonant cavity data measured in organic soil samples comes at the cost of the derived simple model's accuracy as can be seen from the statistics in Table 4. However, this is acceptable given the fact that the foreseen utilization is in global coarse-scale remote sensing applications. The simple generic dielectric model for organic substrates is currently being tested in the L-MEB radiative transfer model as well as integrated in the SMOS Soil Moisture Level 2 Prototype Processor (SML2PP) in prospect of its implementation in the operational one.

The benefit of the Mironov et al. dielectric models for organic soil layers is their temperaturedependency. However, as already addressed in Section 2.3, Mironov et al. [30] found the change of $\varepsilon$ throughout the positive temperature range to be marginal. Thus, this criterion is not of major relevance in satellite soil moisture retrieval algorithms. Nevertheless, the ability to model temperature-dependence could be of high interest for satellite data applications where negative temperatures come into play, such as the generation of freeze-thaw or snow-related products. Ideally, in the future common efforts with the research team of V. Mironov should be undertaken to merge the virtues of the simple empirical approach and the Mironov et al. organic models. The globally unavailable information on the organic substrate's bulk density should be omitted. The major importance of this parameter is questionnable as demonstrated by the agreement of relative permittivity trends obtained from resonant cavity measurements on a variety of organic samples with different bulk densities (Table 1) and the Mironov et al. [30] and Mironov and Savin [31] data where the collected organic material had been packed to significantly higher bulk densities as what had been measured in situ. The model should be calibrated on a complete relative permittivity dataset combining all data used in the different studies. Optimally, new temperature-dependent relative permittivity measurements spanning the negative and positive temperature ranges and using an efficient temperature control should also be included.

\section{Conclusions}

The objective of the here presented work in the scope of ESA's "SMOSHiLat" project was to improve our currently insufficient knowledge of L-band emissions of organic surface layers by means of L-band permittivity measurements as well as to evaluate the two existing dielectric modes for organic substrates by Mironov et al. [30] and Mironov and Savin [31]. To this end, L-band relative permittivity measurements were carried out on a wealth of samples from organic surface horizons from different regions (Denmark, Finland, Scotland and Siberia), spanning a wide range of organic substrate types. Where available, measurements of samples from the underlying sandy mineral A-horizons were included for cross-comparison. The here presented data was measured at room temperature using the resonant cavity (weak perturbation, $1.26 \mathrm{GHz}$ ) technique. This method yielded satisfactory results for organic substrates over the entire wetness range after the height of the tube containing the sample inserted into the resonant cavity was adjusted. The necessary specific calibration of the alpha-factor used for the calculation of $\varepsilon$ was carried out by means of standard acetic acid-water mixtures.

The obtained datasets for organic and sandy mineral substrates showed uniform trends with increasing relative permittivity as the water content increases, though with a noticeable spread in the data measured from samples of organic character. Neither in case of the datasets obtained from mineral nor organic soil material there was a distinct difference in the behavior of measurements on samples from different sites. This implies that generally, a uniform dielectric response, and thus, L-band emission behavior can be expected from organic soil layers. These findings allowed the fitting of simple empirical models through the water content-relative permittivity couples obtained from mineral and organic soil samples, respectively. These models turned out to be consistent with the theory of increased bound water fraction (where water molecules are rotationally hindered) in organic substrates, and thus, lower $\varepsilon$ compared to the sandy mineral soils, as well as with earlier published findings by Bircher et al. [44] using conventional in situ soil moisture sensors. 
The simple empirical model for sandy mineral soils agreed well with corresponding simulations using the Mironov mineral model and underlined its validity in the high sandy texture range. Respective output from the Dobson et al. [16] mineral model showed constantly positively biased values of $\varepsilon^{\prime}$ and unrealistic behavior of $\varepsilon^{\prime \prime}$, most likely due to the fact that this dielectric model was not calibrated for sandy soils. At the same time, our simple empirical model for organic substrates compared well with outputs of the Mironov et al. [30] and Mironov and Savin [31] organic models. This general consensus strengthens confidence in the validity of all of these dielectric models for organic substrates. Compared to the more sophisticated Mironov et al. models that are based on organic samples from only one specific region, the newly developed empirical model considers a significant variety of organic substrate types. Furthermore, it is calibrated over the entire expected wetness range and does not require globally unavailable auxiliary input data. Hence, it should be generically applicable wherever organic soil surface layers are present (also in lower latitude regions), and thus, should be suited for its purpose, namely the application in coarse-resolution L-band microwave satellite soil moisture retrieval algorithms. Currently, the model is being tested in the SMOS Soil Moisture Level 2 Prototype Processor (SML2PP) in prospect of its implementation in the operational one. The temperature-dependent Mironov et al. dielectric models for organic substrates should be exploited for use in satellite data applications where negative temperatures are one of the major drivers (e.g., freeze-thaw, permafrost or snow-related products). Ideally, in the future, common efforts with the research team of $\mathrm{V}$. Mironov should be undertaken to merge the advantages of the simple empirical approach and the Mironov et al. organic models.

Acknowledgments: Financial support for conducting this research by the following institutions is gratefully acknowledged: European Space Agency (Support to Science Element-Changing Earth Science Network and Expert Support Laboratory); Centre National d'Etudes Spatiales (Terre, Océans, Surfaces Continentales, Atmosphère Programme, TOSCA), France. We would further like to express our gratitude to the staffs of the Danish Hydrological Observatory HOBE and the Finnish Meteorological Institute for their technical and logistical support during sample collection at their study sites. Last but not least, we would like to thank Christian Mätzler (Gamma Remote Sensing, Switzerland), Mike Schwank (Swiss Federal Institute for Forest, Snow and Landscape Research WSL and Gamma Remote Sensing, Switzerland) and Jeffrey E. Campbell (Campbell Consulting LLC, Boise, ID, USA) for their valuable inputs in the course of this work.

Author Contributions: François Demontoux and Simone Bircher conceived and designed the experiments; François Demontoux, Stephen Razafindratsima and Simone Bircher performed the experiments; François Demontoux and Simone Bircher analyzed the data; Elena Zakharova, Yann H. Kerr and Simone Bircher contributed soil materials; François Demontoux contributed analysis tools; Jean-Pierre Wigneron, Matthias Drusch, Yann H. Kerr, and Simone Bircher provided scientific expertise; Simone Bircher wrote the paper.

Conflicts of Interest: The authors declare no conflict of interest.

\section{References}

1. Zimov, S.A.; Schuur, E.; Chapin, F. Climate change: Permafrost and the global carbon budget. Science 2006, 312, 1612-1613. [CrossRef] [PubMed]

2. Tarnocai, C.; Canadell, J.G.; Schuur, E.A.G.; Kuhry, P.; Mazhitova, G.; Zimov, S. Soil organic carbon pools in the northern circumpolar permafrost region: Soil organic carbon pools. Glob. Biogeochem. Cycles 2009, 23. [CrossRef]

3. Hansen, J.; Sato, M.; Ruedy, R.; Lo, K.; Lea, D.W.; Medina-Elizade, M. Global temperature change. Proc. Natl. Acad. Sci. USA 2006, 103, 14288-14293. [CrossRef] [PubMed]

4. Collins, M.; Knutti, R.; Arblaster, J.; Dufresne, T.; Fichefet, T.; Friedlingstein, P.; Gao, X.; Gutowski, W.J.; Johns, T.; Krinner, G.; et al. Long-term climate change: Projections, commitments and irreversibility. In Climate Change 2013: The Physical Science Basis. Contribution of Working Group I to the Fifth Assessment Report of the Intergovernmental Panel on Climate Change; Stocker, T.F., Qin, D., Plattner, G.-K., Tignor, M., Allen, S.K., Boschung, J., Nauels, A., Xia, Y., Bex, V., Midgley, P.M., Eds.; Cambridge University Press: Cambridge, UK; New York, NY, USA, 2013.

5. Stokstad, E. Defrosting the carbon freezer of the North. Science 2004, 304, 1618. [CrossRef] [PubMed] 
6. Schuur, E.A.G.; Bockheim, J.; Canadell, J.G.; Euskirchen, E.; Field, C.B.; Goryachkin, S.V.; Hagemann, S.; Kuhry, P.; Lafleur, P.M.; Lee, H.; et al. Vulnerability of permafrost carbon to climate change: Implications for the global carbon cycle. BioScience 2008, 58, 701. [CrossRef]

7. Schuur, E.A.G.; Abbott, B. Climate change: High risk of permafrost thaw. Nature 2011, 480, 32-33. [CrossRef] [PubMed]

8. Davidson, E.A.; Janssens, I.A. Temperature sensitivity of soil carbon decomposition and feedbacks to climate change. Nature 2006, 440, 165-173. [CrossRef] [PubMed]

9. Kerr, Y.H.; Waldteufel, P.; Wigneron, J.-P.; Martinuzzi, J.; Font, J.; Berger, M. Soil moisture retrieval from space: The Soil Moisture and Ocean Salinity (SMOS) mission. IEEE Trans. Geosci. Remote Sens. 2001, 39, 1729-1735. [CrossRef]

10. Kerr, Y.H.; Waldteufel, P.; Wigneron, J.-P.; Delwart, S.; Cabot, F.; Boutin, J.; Escorihuela, M.-J.; Font, J.; Reul, N.; Gruhier, C.; et al. The SMOS mission: New tool for monitoring key elements ofthe global water cycle. Proc. IEEE 2010, 98, 666-687. [CrossRef]

11. Wagner, W.; Blöschl, G.; Pampaloni, P.; Calvet, J.-C.; Bizzarri, B.; Wigneron, J.-P.; Kerr, Y. Operational readiness of microwave remote sensing of soil moisture for hydrologic applications. Hydrol. Res. 2007, 38, 1-20. [CrossRef]

12. Lagerloef, G.; Colomb, F.R.; Le Vine, D.; Wentz, F.; Yueh, S.; Ruf, C.; Lilly, J.; Gunn, J.; Chao, Y.; deCharon, A.; et al. The aquarius/SAC-D mission: Designed to meet the salinity remote-sensing challenge. Oceanography 2008, 21, 68-81. [CrossRef]

13. Entekhabi, D.; Njoku, E.G.; O’Neill, P.E.; Kellogg, K.H.; Crow, W.T.; Edelstein, W.N.; Entin, J.K.; Goodman, S.D.; Jackson, T.J.; Johnson, J.; et al. The Soil Moisture Active Passive (SMAP) mission. Proc. IEEE 2010, 98, 704-716. [CrossRef]

14. Mo, T.; Choudhury, B.J.; Schmugge, T.J.; Wang, J.R.; Jackson, T.J. A model for microwave emission from vegetation-covered fields. J. Geophys. Res. 1982, 87, 11229. [CrossRef]

15. Wigneron, J.-P.; Chanzy, A.; Calvet, J.-C.; Bruguier, N. A simple algorithm to retrieve soil moisture and vegetation biomass using passive microwave measurements over crop fields. Remote Sens. Environ. 1995, 51, 331-341. [CrossRef]

16. Dobson, M.; Ulaby, F.; Hallikainen, M.; El-Rayes, M. Microwave dielectric behavior of wet soil-Part II: Dielectric mixing models. IEEE Trans. Geosci. Remote Sens. 1985, GE-23, 35-46. [CrossRef]

17. Peplinski, N.R.; Ulaby, F.T.; Dobson, M.C. Dielectric properties of soils in the $0.3-1.3-G H z$ range. IEEE Trans. Geosci. Remote Sens. 1995, 33, 803-807. [CrossRef]

18. Mironov, V.L.; Dobson, M.C.; Kaupp, V.H.; Komarov, S.A.; Kleshchenko, V.N. Generalized refractive mixing dielectric model for moist soils. IEEE Trans. Geosci. Remote Sens. 2004, 42, 773-785. [CrossRef]

19. Mironov, V.L.; Kosolapova, L.G.; Fomin, S.V. Physically and mineralogically based spectroscopic dielectric model for moist soils. IEEE Trans. Geosci. Remote Sens. 2009, 47, 2059-2070. [CrossRef]

20. Mironov, V.; Kerr, Y.; Wigneron, J.-P.; Kosolapova, L.; Demontoux, F. Temperature- and texture-dependent dielectric model for moist soils at 1.4 GHz. IEEE Geosci. Remote Sens. Lett. 2013, 10, 419-423. [CrossRef]

21. Mironov, V.L.; Fomin, S.V. Temperature and mineralogy dependable model for microwave dielectric spectra of moist soils. PIERS Online 2009, 5, 411-415. [CrossRef]

22. Kerr, Y.; Waldteufel, P.; Richaume, P.; Ferrazzoli, P.; Wigneron, J.-P. SMOS Level 2 Processor for Soil Moisture Algorithm Theoretical Basis Document (ATBD) V4.a; SM-ESL (CBSA): Toulouse, France, 2015; p. 131.

23. Mialon, A.; Richaume, P.; Leroux, D.; Bircher, S.; Bitar, A.A.; Pellarin, T.; Wigneron, J.-P.; Kerr, Y.H. Comparison of dobson and mironov dielectric models in the SMOS soil moisture retrieval algorithm. IEEE Trans. Geosci. Remote Sens. 2015, 53, 3084-3094. [CrossRef]

24. Bircher, S.; Balling, J.E.; Skou, N.; Kerr, Y.H. Validation of SMOS brightness temperatures during the HOBE airborne campaign, Western Denmark. IEEE Trans. Geosci. Remote Sens. 2012, 50, 1468-1482. [CrossRef]

25. Srivastava, P.K.; O’Neill, P.; Cosh, M.; Kurum, M.; Lang, R.; Joseph, A. Evaluation of dielectric mixing models for passive microwave soil moisture retrieval using data from ComRAD ground-based SMAP simulator. IEEE J. Sel. Top. Appl. Earth Obs. Remote Sens. 2015, 8, 4345-4354. [CrossRef]

26. Kellner, E.; Lundin, L.-C. Calibration of time domain reflectometry for water content in peat soil. Hydrol. Res. 2001, 32, 315-332.

27. Li, H.; Parent, L.E.; Karam, A.; Tremblay, C. Potential of sphagnum peat for improving soil organic matter, water holding capacity, bulk density and potato yield in a sandy soil. Plant Soil 2004, 265, 355-365. [CrossRef] 
28. Jones, S.B.; Wraith, J.M.; Or, D. Time domain reflectometry measurement principles and applications. Hydrol. Process. 2002, 16, 141-153. [CrossRef]

29. Mironov, V.L.; De Roo, R.D.; Savin, I.V. Temperature-dependable microwave dielectric model for an arctic soil. IEEE Trans. Geosci. Remote Sens. 2010, 48, 2544-2556. [CrossRef]

30. Mironov, V.L.; Kerr, Y.H.; Kosolapova, L.G.; Savin, I.V.; Muzalevskiy, K.V. A temperature-dependent dielectric model for thawed and frozen organic soil at 1.4 GHz. IEEE J. Sel. Top. Appl. Earth Obs. Remote Sens. 2015, 8, 4470-4477. [CrossRef]

31. Mironov, V.; Savin, I. A temperature-dependent multi-relaxation spectroscopic dielectric model for thawed and frozen organic soil at 0.05-15 GHz. Phys. Chem. Earth Parts ABC 2015, 83-84, 57-64. [CrossRef]

32. Bircher, S.; Kerr, Y.H.; Wigneron, J.-P. SMOSHiLat-Microwave L-Band Emissions from Organic-Rich Soils in the Northern Cold Climate Zone and Their Impact on the SMOS Soil Moisture Product; Support to Science Element-Changing Earth Science Network; ESA-ESRIN: Frascati, Italy, 2015; p. 71.

33. Jensen, K.H.; Illangasekare, T.H. HOBE: A hydrological observatory. Vadose Zone J. 2011, 10, 1. [CrossRef]

34. Bircher, S.; Skou, N.; Jensen, K.H.; Walker, J.P.; Rasmussen, L. A soil moisture and temperature network for SMOS validation in Western Denmark. Hydrol. Earth Syst. Sci. 2012, 16, 1445-1463. [CrossRef]

35. Ikonen, J.; Vehviläinen, J.; Rautiainen, K.; Smolander, T.; Lemmetyinen, J.; Bircher, S.; Pulliainen, J. The Sodankylä in situ soil moisture observation network: An example application of ESA CCI soil moisture product evaluation. Geosci. Instrum. Methods Data Syst. 2016, 5, 95-108. [CrossRef]

36. Zanella, A.; Jabiol, B.; Ponge, J.-F.; Sartori, G.; De Waal, R.; Van Delft, B.; Graefe, U.; Cools, N.; Katzensteiner, K.; Hager, H.; et al. European Humus Forms Reference Base. Available online: http:/ / hal.archives-ouvertes.fr/hal-00541496 (accessed on 8 April 2016).

37. Ball, D.F. Loss-on-ignition as an estimate of organic matter and organic carbon in non-calcareous soils. J. Soil Sci. 1964, 15, 84-92. [CrossRef]

38. Heiri, O.; Lotter, A.F.; Lemcke, G. Loss on ignition as a method for estimating organic and carbonate content in sediments: Reproducibility and comparability of results. J. Paleolimnol. 2001, 25, 101-110. [CrossRef]

39. Boudouris, G. Validité de la méthode de perturbation appliquée aux cavités résonnantes pour la mesure de la perméabilité et de la permittivité des petits échantillons. Ann. Télécommun. 1964, 19, 63-80.

40. Demontoux, F.; Razafindratsima, S.; Bircher, S.; Ruffié, G.; Bonnaudin, G.; Jonard, F.; Wigneron, J.-P.; Sbartai, M.; Kerr, Y. Efficiency of end effect probes for in-situ permittivity measurements in the 0.5-6 GHz frequency range and their application for organic soil horizons study. Sens. Actuators A Phys. 2016. accepted. [CrossRef]

41. O'Kelly, B.C. Accurate determination of moisture content of organic soils using the oven drying method. Dry. Technol. 2004, 22, 1767-1776. [CrossRef]

42. Schaap, M.G.; de Lange, L.; Heimovaara, T.J. TDR calibration of organic forest floor media. Soil Technol. 1997, 11, 205-217. [CrossRef]

43. Pumpanen, J.; Ilvesniemi, H. Calibration of time domain reflectometry for forest soil humus layers. Boreal Environ. Res. 2005, 10, 589-595.

44. Bircher, S.; Andreasen, M.; Vuollet, J.; Vehviläinen, J.; Rautiainen, K.; Jonard, F.; Weihermüller, L.; Zakharova, E.; Wigneron, J.-P.; Kerr, Y.H. Soil moisture sensor calibration for organic soil surface layers. Geosci. Instrum. Methods Data Syst. 2016, 5, 109-125. [CrossRef]

45. National Aeronautics and Space Administration (NASA). Global Land Data Assimilation Systems (GLDAS) Land Surface Parameters. Available online: http://ldas.gsfc.nasa.gov/gldas/GLDASsoils.php (accessed on 12 August 2016).

(C) 2016 by the authors; licensee MDPI, Basel, Switzerland. This article is an open access article distributed under the terms and conditions of the Creative Commons Attribution (CC-BY) license (http://creativecommons.org/licenses/by/4.0/). 